\title{
Predicting Some Physicochemical Properties of Octane Isomers: A Topological Approach Using ev-Degree and ve-Degree Zagreb Indices
}

\author{
Süleyman Ediz \\ Faculty of Education, Van Yüzüncü Yıl University, Van, Turkey
}

Email address:

suleymanediz@yyu.edu.tr

\section{To cite this article:}

Süleyman Ediz. Predicting Some Physicochemical Properties of Octane Isomers: A Topological Approach Using ev-Degree and ve-Degree Zagreb Indices. International Journal of Systems Science and Applied Mathematics. Vol. 2, No. 5, 2017, pp. 87-92.

doi: 10.11648/j.ijssam.20170205.12

Received: August 22, 2017; Accepted: September 6, 2017; Published: October 17, 2017

\begin{abstract}
Topological indices have important role in theoretical chemistry for QSPR researches. Among the all topological indices the Randic and the Zagreb indices have been used more considerably than any other topological indices in chemical and mathematical literature. Most of the topological indices as in the Randić and the Zagreb indices are based on the degrees of the vertices of a connected graph. Recently novel two degree concepts have been defined in graph theory; $e v$-degrees and $v e$ degrees. In this study $e v$-degree Zagreb index, ve-degree Zagreb indices and ve-degree Randić index are defined by using these new graph invariants as parallel to their corresponding classical degree versions. These new group $e v$-degree and $v e$-degree indices are compared with the other well-known and most used topological indices in literature such as; Wiener, Zagreb and Randić indices by modelling some physicochemical properties of octane isomers. The $e v$-degree Zagreb index, the ve-degree Zagreb and the ve-degree Randić indices give better correlation than Wiener, Zagreb and Randić indices to predict the some specific physicochemical properties of octanes. The relations between the second Zagreb index and $e v$-degree and $v e$-degree Zagreb indices and some mathematical properties of $e v$-degree and ve-degree Zagreb indices are investigated.
\end{abstract}

Keywords: $e v$-Degree Zagreb Index, Octane Isomers, QSPR, QSAR, ve-Degree Randić Index, ve-Degree Zagreb Indices

\section{Introduction}

Graph theory which is an important branch of applied mathematics has many applications to modelling real world problems from science to technology. Chemical graph theory which is a fascinating branch of graph theory has many applications related to chemistry. Chemical graph theory provides many information about molecules and atoms by using pictorial representation (chemical graph) of these chemical compounds. A topological index which is a numerical quantity derived from the chemical graph of a molecule is used to modelling chemical and physical properties of molecules in QSPR/QSAR researches. Quantitative structure-property/activity relationships (QSPR/QSAR) studies have very important role in theoretical chemistry. Octane isomers have been used widely in QSPR studies. The role of octane isomers in QSPR studies, we refer the interested reader [1-4] and references therein. Among the all topological indices, Wiener, Randić and Zagreb indices are the most used topological indices in the chemical and mathematical literature so far.

Very recently, Chellali, Haynes, Hedetniemi and Lewis have published a seminal study: On ve-degrees and $e v$-degrees in graphs [5]. The authors defined two novel degree concepts in graph theory; $e v$-degrees and ve-degrees and investigate some basic mathematical properties of both novel graph invariants with regard to graph regularity and irregularity [5]. After given the equality of the total $e v$-degree and total ve-degree for any graph, also the total $e v$-degree and the total ve-degree were stated as in relation to the first Zagreb index. It was proposed in the article that the chemical applicability of the total evdegree (and the total ve-degree) could be an interesting problem in view of chemistry and chemical graph theory.

In this study, ev-degree Zagreb index, ve-degree Zagreb indices and ve-degree Randić index are defined by using these new graph invariants. Tthese novel topological indices are 
defined by as parallel to corresponding original definitions of based on classical degree concept. These new group $e v$-degree, ve-degree Zagreb and ve-degree Randić indices are compared with the other well-known and most used topological indices such as Wiener, Zagreb and Randić indices by modelling some physicochemical properties of octane isomers.

\section{Preliminaries}

In this section some basic and preliminary concepts will be given which shall be used later. A graph $G=(V, E)$ consists of two nonempty sets $V$ and 2-element subsets of $V$ namely $E$. The elements of $V$ are called vertices and the elements of $E$ are called edges. For a vertex $v, \operatorname{deg}(v)$ show the number of edges that incident to $v$. The set of all vertices which adjacent to $v$ is called the open neighborhood of $v$ and denoted by $N(v)$. If we add the vertex $v$ to $N(v)$, then we get the closed neighborhood of $v, N[v]$. For the vertices $u$ and $v$, $d(u, v)$ denotes the distance between $u$ and $v$ which means that minimum number of edges between $u$ and $v$. In [6], the Wiener index of a connected graph $G$, the first topological index, was defined as;

$$
W=W(G)=\frac{1}{2} \sum_{u, v \in V(G)} d(u, v) .
$$

In his study, Wiener used the total distance between all different atoms (vertices) of paraffin to predict boiling point. We refer the interested reader to [7-9] and the references therein for the detailed discussion of Wiener index. The first and second Zagreb indices [10] defined as follows: The first Zagreb index of a connected graph $G$, defined as;

$$
M_{1}=M_{1}(G)=\sum_{u \in V(G)} \operatorname{deg}(u)^{2}=\sum_{u v \in E(G)}(\operatorname{deg}(u)+\operatorname{deg}(v)) .
$$

And the second Zagreb index of a connected graph $G$, defined as;

$$
M_{2}=M_{2}(G)=\sum_{u v \in E(G)} \operatorname{deg}(u) \cdot \operatorname{deg}(v) .
$$

The authors investigated the relationship between the total $\pi$-electron energy on molecules and Zagreb indices [10]. For the details see the references [11-13]. Randić investigated the measuring the extent of branching of the carbon-atom skeleton of saturated hydrocarbons via Randić index [14]. The Randić index of a connected graph $G$ defined as;

$$
R=R(G)=\sum_{u v \in E(G)}(\operatorname{deg}(u) \cdot \operatorname{deg}(v))^{-1 / 2} .
$$

The interested reader should see to [15-17] and the references therein for the up to date arguments about the Randić index. And now the definitions of $e v$-degree and ve-degree concepts are given which were given by Chellali et al. in [5].

Definition 2.1 [5] Let $G$ be a connected graph and $v \in$ $V(G)$. The ve-degree of the vertex $v, \operatorname{deg}_{v e}(v)$, equals the number of different edges that incident to any vertex from the closed neighborhood of $v$. For convenience the ve-degree of the vertex $v$ is showed by $c_{v}$.

Definition 2.2 [5] Let $G$ be a connected graph and $e=$ $u v \in E(G)$. The $e v$-degree of the edge $e, \operatorname{deg}_{e v}(e)$, equals the number of vertices of the union of the closed neighborhoods of $u$ and $v$. For convenience the $e v$-degree of the edge $e=u v$ is showed by $c_{e}$ or $c_{u v}$.

These new degree definitions are illustrated for the vertices and edges of the graph $G$ which are shown in Figure 1.

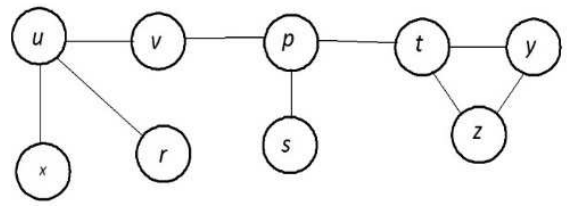

Figure 1. The graph $G$ for the Example 2.3 and Example 2.13.

Example 2.3 Notice that for the vertices of $G$, we get $c_{x}=3, c_{u}=4, c_{v}=6, c_{r}=3, c_{p}=6, c_{s}=3, c_{t}=6$, $c_{z}=4$ and $c_{y}=4$. And for the edges of $G$, we get $c_{x u}=4$, $c_{u v}=5, c_{u r}=4, c_{v p}=5, c_{p t}=6, c_{p s}=4, c_{t z}=4$, $c_{t y}=4$ and $c_{y z}=3$.

Definition 2.4 [5] Let $G$ be a connected graph and $v \in$ $V(G)$. The total ev-degree of the graph $G$ is defined as;

$$
T_{e}=T_{e}(G)=\sum_{e \in E(G)} c_{e} .
$$

And the total ve-degree of the graph $G$ is defined as;

$$
T_{v}=T_{v}(G)=\sum_{v \in V(G)} c_{v} .
$$

Observation 2.5 [5] For any connected graph G,

$$
T_{e}(G)=T_{v}(G) .
$$

The following theorem states the relationship between the first Zagreb index and the total ve-degree of a connected graph $G$.

Theorem 2.6 [5] For any connected graph G,

$$
T_{e}(G)=T_{v}(G)=M_{1}(G)-3 n(G) .
$$

where $n(G)$ denotes the total number of triangles in $\mathrm{G}$.

Theorem 2.1 can be restated for the trees which are acyclic and are not contain any triangles.

Corollary 2.7 For any tree $T$,

$$
T_{e}(T)=T_{v}(T)=M_{1}(T) .
$$

And from this last equality, naturally is considered to apply these two novel degree concepts to chemical graph theory by introducing $e v$-degree and ve-degree Zagreb indices as well as ve-degree Randić index.

Definition 2.8 Let $G$ be a connected graph and $e \in E(G)$. The $e v$-degree Zagreb index of the graph $G$ is defined as;

$$
S=S(G)=\sum_{e \in E(G)} c_{e}^{2} .
$$

Definition 2.9 Let $G$ be a connected graph and $v \in V(G)$. The first ve-degree Zagreb alpha index of the graph $G$ is defined as;

$$
S^{\alpha}=S^{\alpha}(G)=\sum_{v \in V(G)} c_{v}^{2}
$$

Definition 2.10 Let $G$ be a connected graph and $u v \in$ 
$E(G)$. The first ve-degree Zagreb beta index of the graph $G$ is defined as;

$$
S^{\beta}=S^{\beta}(G)=\sum_{u v \in E(G)}\left(c_{u}+c_{v}\right) .
$$

Definition 2.11 Let $G$ be a connected graph and $u v \in$ $E(G)$. The second ve-degree Zagreb index of the graph $G$ is defined as;

$$
S^{\mu}=S^{\mu}(G)=\sum_{u v \in E(G)} c_{u} c_{v} .
$$

Definition 2.12 Let $G$ be a connected graph and $u v \in E(G)$. The ve-degree Randić index of the graph $G$ is defined as;

$$
R^{\alpha}(G)=\sum_{u v \in E(G)}\left(c_{u} c_{v}\right)^{-1 / 2} .
$$

Example 2.13 These novel topological indices are computed for the graph $G$ in the Example 2.3 (see Figure 1).

$$
\begin{gathered}
S=S(G)=\sum_{e \in E(G)} c_{e}^{2}=175, S^{\alpha}=S^{\alpha}(G)=\sum_{v \in V(G)} \quad{ }_{v}^{2}= \\
183, S^{\beta}=S^{\beta}(G)=\sum_{u v \in E(G)}\left(c_{u}+c_{v}\right)=84, \\
S^{\mu}=S^{\mu}(G)=\sum_{u v \in E(G)} c_{u} c_{v}=202, \\
R^{\alpha}(G)=\sum_{u v \in E(G)} 1 /\left(c_{u} c_{v}\right)^{1 / 2}=13.425 \text { and } M_{2}(G)=46 .
\end{gathered}
$$

\section{Results and Discussions}

In this section all above mentioned old and new topological indices are compared with each other by using strong correlation coefficients acquired from the chemical graphs of octane isomers. The experimental results are got at the www.moleculardescriptors.eu (see Table 1). The following physicochemical features have been modeled:

- Entropy,

- Acentric factor (Acen Fac),

- Enthalpy of vaporization (HVAP),

-Standard enthalpy of vaporization (DHVAP).

Those physicochemical properties of octane isomers are selected for which give reasonably good correlations, i.e. the absolute value of correlation coefficients are larger than 0.8 except from the property HVAP (see Table 2). Also, the
Wiener index, the first Zagreb index, the second Zagreb index and the Randić indices of octane isomers values are retrieved at the www.moleculardescriptors.eu (see Table 3). The ev-degree Zagreb index, the ve-degree Zagreb indices and the ve-degree Randić index of octane isomers values are showed in Table 3.

\begin{tabular}{|c|c|c|c|c|c|c|c|c|c|}
\hline Molecule & $\mathbf{M}_{1}$ & $\mathbf{M}_{2}$ & W & $\mathbf{R}$ & $\mathbf{S}$ & $\mathbf{S \alpha}$ & $\mathbf{S \beta}$ & $\mathbf{S \mu}$ & $\mathbf{R \alpha}$ \\
\hline n-octane & 26 & 24 & 84 & 3.914 & 98 & 90 & 48 & 84 & 2.144 \\
\hline 2-methyl-heptane & 28 & 26 & 79 & 3.770 & 114 & 104 & 52 & 98 & 1.971 \\
\hline 3-methyl-heptane & 28 & 27 & 76 & 3.808 & 116 & 98 & 54 & 106 & 1.956 \\
\hline 4-methyl-heptane & 28 & 27 & 75 & 3.808 & 116 & 110 & 54 & 107 & 1.991 \\
\hline 3-ethyl-hexane & 28 & 28 & 72 & 3.846 & 118 & 114 & 56 & 115 & 1.964 \\
\hline 2,2-dimethyl-hexane & 32 & 30 & 71 & 3.561 & 152 & 138 & 60 & 132 & 1.754 \\
\hline 2,3-dimethyl-hexane & 30 & 30 & 70 & 3.681 & 134 & 126 & 60 & 129 & 1.784 \\
\hline 2,5-dimethyl-hexane & 30 & 28 & 74 & 3.626 & 130 & 118 & 56 & 113 & 1.801 \\
\hline 3,3-dimethyl-hexane & 32 & 32 & 67 & 3.621 & 156 & 146 & 64 & 148 & 1.718 \\
\hline 3,4-dimethyl-hexane & 30 & 31 & 68 & 3.719 & 136 & 130 & 62 & 136 & 1.753 \\
\hline 2-methyl-3-ethyl-pentane & 30 & 31 & 67 & 3.719 & 136 & 132 & 62 & 137 & 1.770 \\
\hline 3-methyl-3-ethyl-pentane & 32 & 34 & 64 & 3.682 & 160 & 152 & 68 & 163 & 1.645 \\
\hline 2,2,3-trimethyl-pentane & 34 & 35 & 63 & 3.481 & 174 & 162 & 70 & 171 & 1.527 \\
\hline 2,2,4-trimethyl-pentane & 34 & 32 & 66 & 3.417 & 168 & 156 & 64 & 147 & 1.606 \\
\hline 2,2,3,3-tetramethylbutane & 38 & 40 & 58 & 3.250 & 214 & 194 & 80 & 217 & 1.277 \\
\hline
\end{tabular}

Table 1. Some physicochemical properties of octane isomers.

\begin{tabular}{lllll}
\hline Molecule & Entropy & Acen Fac & HVAP & DHVAP \\
\hline n-octane & 111.70 & 0.39790 & 73.19 & 9.915 \\
2-methyl-heptane & 109.80 & 0.37792 & 70.30 & 9.484 \\
3-methyl-heptane & 111.30 & 0.37100 & 71.30 & 9.521 \\
4-methyl-heptane & 109.30 & 0.37150 & 70.91 & 9.483 \\
3-ethyl-hexane & 109.40 & 0.36247 & 71.70 & 9.476 \\
2,2-dimethyl-hexane & 103.40 & 0.33943 & 67.70 & 8.915 \\
2,3-dimethyl-hexane & 108.00 & 0.34825 & 70.20 & 9.272 \\
2,4-dimethyl-hexane & 107.00 & 0.34422 & 68.50 & 9.029 \\
2,5-dimethyl-hexane & 105.70 & 0.35683 & 68.60 & 9.051 \\
3,3-dimethyl-hexane & 104.70 & 0.32260 & 68.50 & 8.973 \\
3,4-dimethyl-hexane & 106.60 & 0.34035 & 70.20 & 9.316 \\
2-methyl-3-ethyl-pentane & 106.10 & 0.33243 & 69.70 & 9.209 \\
3-methyl-3-ethyl-pentane & 101.50 & 0.30690 & 69.30 & 9.081 \\
2,2,3-trimethyl-pentane & 101.30 & 0.30082 & 67.30 & 8.826 \\
2,2,4-trimethyl-pentane & 104.10 & 0.30537 & 64.87 & 8.402 \\
2,3,3-trimethyl-pentane & 102.10 & 0.29318 & 68.10 & 8.897 \\
2,3,4-trimethyl-pentane & 102.40 & 0.31742 & 68.37 & 9.014 \\
2,2,3,3-tetramethylbutane & 93.06 & 0.25529 & 66.20 & 8.410 \\
\hline
\end{tabular}

Table 2. The correlation coefficients between new and old topological indices and some physicochemical properties of octane isomers.

\begin{tabular}{lllll}
\hline Index & Entropy & AcenFac & HVAP & DHVAP \\
\hline $\mathrm{S}$ & -0.9614 & -0.9829 & -0.8425 & -0.9043 \\
$\mathrm{~S} \alpha$ & -0.9565 & -0.9906 & -0.8279 & -0.8931 \\
$\mathrm{~S} \beta$ & -0.9410 & -0.9864 & -0.7281 & -0.8118 \\
$\mathrm{~S} \mu$ & -0.9481 & -0.9863 & -0.7552 & -0.8118 \\
$\mathrm{R} \alpha$ & 0.9486 & 0.9829 & 0.8351 & 0.8924 \\
$\mathrm{~W}$ & 0.8772 & 0.9656 & 0.7381 & 0.8202 \\
$\mathrm{M}_{1}$ & -0.9543 & -0.9731 & -0.8860 & -0.9361 \\
$\mathrm{M}_{2}$ & -0.9410 & -0.9864 & -0.7281 & -0.8118 \\
$\mathrm{R}$ & 0.9063 & 0.9043 & 0.9359 & 0.9580 \\
\hline
\end{tabular}

Table 3. Topological indices of octane isomers. 
Table 4. The squares of correlation coefficients between topological indices and some physicochemical properties of octane isomers.

\begin{tabular}{lllll}
\hline Index & Entropy & AcenFac & HVAP & DHVAP \\
\hline $\mathrm{S}$ & 0.9242 & 0.9660 & 0.7098 & 0.8177 \\
$\mathrm{~S} \alpha$ & 0.9148 & 0.9812 & 0.6854 & 0.7976 \\
$\mathrm{~S} \beta$ & 0.8854 & 0.9729 & 0.5301 & 0.6590 \\
$\mathrm{~S} \mu$ & 0.8988 & 0.9727 & 0.5703 & 0.6590 \\
$\mathrm{R} \alpha$ & 0.8998 & 0.9660 & 0.6973 & 0.7963 \\
$\mathrm{~W}$ & 0.7694 & 0.9323 & 0.5447 & 0.6727 \\
$\mathrm{M}_{1}$ & 0.9106 & 0.9469 & 0.7849 & 0.8762 \\
$\mathrm{M}_{2}$ & 0.8854 & 0.9729 & 0.5301 & 0.6590 \\
$\mathrm{R}$ & 0.8213 & 0.8177 & 0.8759 & 0.9177 \\
\hline
\end{tabular}

It can be seen from the Table 2 that the most convenient indices which are modelling the Entropy, Enthalpy of vaporization (HVAP), Standard enthalpy of vaporization (DHVAP) and Acentric factor (AcenFac) are ve-degree Zagreb index $(S)$ for entropy, the first ve-degree Zagreb alpha index $\left(S^{\alpha}\right)$ for Acentric Factor and the Randic index $(R)$ for the Enthalpy of vaporization (HVAP) and Standard enthalpy of vaporization (DHVAP), respectively. But notice that the first two indices show the negative strong correlation and the third index show the positive strong correlation. Because of this fact these graph invariants are compared with each other by using the squares of correlation coefficients for ensure the compliance between the positive and negative correlation coefficients (see Table 4).

Entropy: It can be seen from the Table 4 that the ve-degree Zagreb index $(S)$ gives the highest square of correlation coefficient for entropy. After that the first ve-degree Zagreb alpha index $\left(S^{\alpha}\right)$, the first Zagreb index $\left(M_{l}\right)$, the ve-degree Randić index $\left(R^{\alpha}\right)$ and the second ve-degree Zagreb index $\left(S^{\mu}\right)$ give the highest square of correlation coefficients, respectively.

Acentric factor (AcenFac): It can be seen from the Table 4 that the first ve-degree Zagreb alpha index $\left(S^{\alpha}\right)$ gives the highest square of correlation coefficient for Acentric factor. After that the first ve-degree Zagreb beta index $\left(S^{\beta}\right)$ and the second Zagreb index $\left(M_{2}\right)$ give the same value. And the the second ve-degree Zagreb index $\left(S^{\mu}\right)$, the ev-degree Zagreb index $(S)$ and ve-degree Randić index $\left(R^{\alpha}\right)$ give the highest square of correlation coefficients, respectively.

Enthalpy of vaporization (HVAP): It can be seen from the Table 4 that the Randić index $(R)$ gives the the highest square of correlation coefficient for Enthalpy of vaporization. After that the first Zagreb index $\left(M_{l}\right)$, the $e v$-degree Zagreb index $(S)$, the ve-degree Randic index $\left(R^{\alpha}\right)$ and the the first vedegree Zagreb alpha index $\left(S^{\alpha}\right)$ give the highest square of correlation coefficients, respectively.

Standard enthalpy of vaporization (DHVAP): It can be observed from the Table 4 that the Randic index $(R)$ gives the the highest square of correlation coefficient for Enthalpy of vaporization. After that the first Zagreb index $\left(M_{l}\right)$, the $e v$ degree Zagreb index $(S)$, the first ve-degree Zagreb alpha index $\left(S^{\alpha}\right)$ and the ve-degree Randić index $\left(R^{\alpha}\right)$ give the highest square of correlation coefficients, respectively.

And now, the relations between the old topological indices and the novel topological indices are investigated. The correlation coefficients between the Wiener, Zagreb, Randić indices and the ev-degree and ve-degree indices are shown in Table 5. It can be shown from the Table 5 that the first vedegree Zagreb beta index $\left(S^{\beta}\right)$ gives the highest absolute value of correlation coefficient with the Wiener index. The $e v$-degree Zagreb index $(S)$ gives the highest correlation coefficient with the first Zagreb index $\left(M_{l}\right)$. The first vedegree Zagreb beta index $\left(S^{\beta}\right)$ gives the highest absolute value of correlation coefficient with the Randić index. And it is very surprisingly see that the correlation coefficient between the second Zagreb index $\left(M_{2}\right)$ and the first ve-degree Zagreb beta index $\left(S^{\beta}\right)$ is one. It can be seen from the Table 3 that $S^{\beta}(G)=2 M_{2}(G)$ for the molecular graphs of octane isomers. But we know that $S^{\beta}(G) \neq 2 M_{2}(G)$ from the Example 2.3. The following section the relation between the second Zagreb index and the first ve-degree Zagreb beta index will be investigated.

Table 5. The correlation coefficients between old and corresponding novel topological indices.

\begin{tabular}{lllll}
\hline Index & $\mathbf{W}$ & $\mathbf{M}_{\mathbf{1}}$ & $\mathbf{M}_{\mathbf{2}}$ & $\mathbf{R}$ \\
\hline $\mathrm{S}$ & -0.9177 & 0.9951 & 0.9676 & -0.9441 \\
$\mathrm{~S} \alpha$ & 0.9483 & 0.9818 & 0.9774 & -0.9182 \\
$\mathrm{~S} \beta$ & -0.9683 & 0.9495 & 1.000 & -0.8609 \\
$\mathrm{~S} \mu$ & -0.9567 & 0.9523 & 0.9982 & -0.8645 \\
$\mathrm{R} \alpha$ & 0.9478 & -0.9764 & -0.9758 & 0.9365 \\
\hline
\end{tabular}

The cross correlation matrix of ev-degree and ve-degree indices are given in Table 6.

Table 6. The cross correlation matrix of the ev-degree and ve-degree topological indices.

\begin{tabular}{llllll}
\hline Index & $\mathbf{S}$ & $\mathbf{S} \boldsymbol{\alpha}$ & $\mathbf{S} \boldsymbol{\beta}$ & $\mathbf{S} \boldsymbol{\mu}$ & $\mathbf{R} \boldsymbol{\alpha}$ \\
\hline $\mathrm{S}$ & 1.0000 & & & & \\
$\mathrm{~S} \alpha$ & 0.9901 & 1.0000 & & & \\
$\mathrm{~S} \beta$ & 0.9676 & 0.9774 & 1.0000 & & \\
$\mathrm{~S} \mu$ & 0.9738 & 0.9797 & 0.9982 & 1.0000 & \\
$\mathrm{R} \alpha$ & -0.9758 & -0.9752 & -0.9758 & -0.9701 & 1.0000 \\
\hline
\end{tabular}

It can be shown from the Table 6 that the minimum correlation efficient among the all ve-degree and $e v$-degree indices is 0.9676 which is indicate strong correlation among all these novel indices. From the above arguments, it can be said that the ve-degree and $e v$-degree indices are possible tools for QSPR researches.

\section{Lower and Upper Bounds of $e v$-Degree and $v e$-Degree Zagreb Indices for General Graphs}

In this section are given the relations between second Zagreb index and ve-degree and $e v$-degree Zagreb indices. And also fundamental mathematical properties of $e v$-degree and ve-degree Zagreb indices are given.

Lemma 4.1 Let $\mathrm{T}$ be a tree and $v \in V(T)$ then,

$$
c_{v}=\sum_{u \in N(v)} \operatorname{deg}(u)
$$


Proof From the Definition 2.1 we know that $c_{v}$ equals the number of different edges incident to any vertex from $N(v)$. Clearly for any tree, this definition corresponds the sum of all degrees of the vertices lie in $N(v)$. Hence

$$
c_{v}=\sum_{u \in N(v)} \operatorname{deg}(u) .
$$

Theorem 4.2 Let $\mathrm{T}$ be a tree with the vertex set $V(T)=$ $\left\{v_{1}, v_{2}, \ldots, v_{n}\right\}$ then

$$
S^{\beta}(T)=2 M_{2}(T)
$$

Proof From the Definition 2.10 and Lemma 4.1 we can directly write

$$
\begin{gathered}
S^{\beta}(T)=\sum_{v_{i} v_{j} \in E(T)}\left(c_{v_{i}}+c_{v_{j}}\right) \\
=\sum_{v_{i} v_{j} \in E(T)}\left(\sum_{w \in N\left(v_{i}\right)} \operatorname{deg}(w)\right. \\
\left.+\sum_{w \in N\left(v_{j}\right)} \operatorname{deg}(w)\right) \\
=\operatorname{deg}\left(v_{1}\right) \sum_{w \in N\left(v_{1}\right)} \operatorname{deg}(w) \\
+\operatorname{deg}\left(v_{2}\right) \sum_{w \in N\left(v_{2}\right)} \operatorname{deg}(w)+\cdots \\
+\operatorname{deg}\left(v_{n}\right) \sum_{w \in N\left(v_{n}\right)} \operatorname{deg}(w)
\end{gathered}
$$

Notice that the above sum contains the multiplication of the degree of end vertices of each edge exactly two times. Hence,

$$
=2 \sum_{u v \in E(T)} \operatorname{deg}(u) \operatorname{deg}(v)=2 M_{2}(T) .
$$

Before we give the following interesting theorem, we mention the forgotten topological index [10]. The forgotten topological index for a connected graph $G$ defined as;

$$
F=F(G)=\sum_{v \in V(G)} \operatorname{deg}(v)^{3}=\sum_{u v \in E(G)}\left(\operatorname{deg}(u)^{2}+\operatorname{deg}(v)^{2}\right) .
$$

It was showed in [18] that the predictive power of the forgotten topological index is very close to the first Zagreb index for the entropy and acentric factor. For further studies about the forgotten topological index we refer to the interested reader [18-20] and references therein.

Theorem 4.3 Let $\mathrm{G}$ be a triangle free connected graph, then;

$$
S(G)=F(G)+2 M_{2}(G) .
$$

Proof. It was showed in [5] that $c_{e}=c_{u v}=\operatorname{deg}(u)+$ $\operatorname{deg}(v)$ for any triangle free graph. By using this equality, we get that;

$$
S=S(G)=\sum_{e=u v \in E(G)} c_{e}^{2}=\sum_{e=u v \in E(G)}(\operatorname{deg}(u)+\operatorname{deg}(v))^{2}
$$

$$
\begin{gathered}
=\sum_{e=u v \in E(G)}\left(\operatorname{deg}(u)^{2}+\operatorname{deg}(v)^{2}\right) \\
\quad+2 \sum_{e=u v \in E(G)} \operatorname{deg}(u) \operatorname{deg}(v) \\
=F(G)+2 M_{2}(G) .
\end{gathered}
$$

We can state the following corollary which describe the relation between the $e v$-degree Zagreb index and the first $v e$ degree Zagreb alpha index for trees by using the Theorem 4.3.

Corollary 4.4 Let $\mathrm{T}$ be a tree then;

$$
S(T)=F(T)+S^{\beta}(T) .
$$

And now we give the maximum and minimum graph classes with respect to $e v$-degree and ve-degree Zagreb indices.

Theorem 4.5 Let $\mathrm{G}$ be a simple connected graph of order $n \geq 3$ vertices then;

$$
16 n-30 \leq S(G) \leq \frac{1}{2} n^{3}(n-1) .
$$

Lower bound is achieved if and only if $G$ is a path and upper bound is achieved if and only if $\mathrm{G}$ is a complete graph.

Proof We get that $c_{e}=c_{u v}=|N(u) \cup N(V)|$ from the definition of ev-degree of any edge of G. $|N(u) \cup N(V)|$ reaches its maximum value for the complete graphs and its minimum value for the path for an edge of $G$. There are $n-3$ edges with their ev-degrees equals 4 and 2 edges with their ev-degrees equals 3 for the n-vertex path. And the evdegrees of all edges of the complete graph are $n$. From this, the desired result is acquired.

Theorem 4.6 Let $\mathrm{T}$ be a tree of order $n \geq 3$ vertices then;

$$
16 n-30 \leq S(T) \leq n^{2}(n-1) .
$$

Lower bound is achieved if and only if $\mathrm{T}$ is a path and upper bound is achieved if and only if $\mathrm{T}$ is a star.

Proof The lower bound comes from Theorem 4.5. From the same arguments of the Theorem 4.5, the maximum tree of the ev-degree Zagreb index is star graph. The ev-degrees of all edges of the star graph are $n$. From this, the proof is completed.

Theorem 4.7 Let $\mathrm{G}$ be a simple connected graph of order $n \geq 5$ vertices then;

$$
16 n-6 \leq S^{\alpha}(G) \leq \frac{1}{4} n^{3}(n-1)^{2} .
$$

Lower bound is achieved if and only if $G$ is a path and upper bound is achieved if and only if $G$ is a complete graphs.

Proof It is known that $c_{u}$ equals the number of different edges that incident to any vertex from the closed neighborhood of $v$. Clearly $c_{u}$ reaches its maximum value for the complete graphs and its minimum value for the path for a vertex of $\mathrm{G}$. There are $n-2$ vertices with their ve-degrees equals 4, 2 vertices with their ve-degrees equals 3 and 2 vertices with their ve-degrees equals 2 . And the ve-degrees of all vertices of the complete graph are $n(n-1) / 2$. From this, 
the desired result is acquired.

Theorem 4.8 Let $\mathrm{T}$ be a tree of order $n \geq 5$ vertices then;

$$
16 n-6 \leq S^{\alpha}(T) \leq n(n-1)^{2} .
$$

Lower bound is achieved if and only if $\mathrm{T}$ is a path and upper bound is achieved if and only if $\mathrm{T}$ is a star.

Proof The lower bound comes from Theorem 4.6. From the same arguments of the Theorem 4.7, the maximum tree of the ve-degree first Zagreb alpha index is star graph. The vedegrees of all vertices of the star graph are

$n-1$. From this, the proof is completed.

Theorem 4.9 Let $\mathrm{G}$ be a simple connected graph of order $n \geq 5$ vertices then;

$$
8 n-16 \leq S^{\beta}(G) \leq \frac{1}{2} n^{2}(n-1)^{2} .
$$

Lower bound is achieved if and only if $\mathrm{G}$ is a path and upper bound is achieved if and only if $\mathrm{G}$ is a complete graph.

Proof The proof is similar the proof of Theorem 4.7.

Theorem 4.10 Let $\mathrm{T}$ be a tree of order $n \geq 5$ vertices then;

$$
16 n-6 \leq S^{\beta}(G) \leq 2 n(n-1) .
$$

Lower bound is achieved if and only if $\mathrm{T}$ is a path and upper bound is achieved if and only if $\mathrm{T}$ is a star.

Proof The proof is similar the proof of Theorem 4.8.

Theorem 4.11 Let $\mathrm{G}$ be a simple connected graph of order $n \geq 5$ vertices then;

$$
16 n-44 \leq S^{\mu}(G) \leq \frac{1}{8} n^{3}(n-1)^{3} .
$$

Lower bound is achieved if and only if $\mathrm{G}$ is a path and upper bound is achieved if and only if $\mathrm{G}$ is a complete graph.

Proof The proof is similar the proof of Theorem 4.7.

Theorem 4.12 Let $\mathrm{T}$ be a tree of order $n \geq 5$ vertices then;

$$
16 n-6 \leq S^{\mu}(T) \leq(n-1)^{3} .
$$

Lower bound is achieved if and only if $\mathrm{T}$ is a path and upper bound is achieved if and only if $\mathrm{T}$ is a star.

Proof The proof is similar the proof of Theorem 4.8.

\section{Conclusion}

It was proposed novel topological indices based on evdegree and ve-degree concept which have been defined very recently in graph theory. It has been shown that these indices can be used as predictive means in QSAR researches. Predictive power of these indices have been tested on by using some physicochemical properties of octanes. Acquired results show that the new $e v$-degree and ve-degree indices give somewhat better results by analogy well-known Wiener, Zagreb and Randić indices. In addition, basic mathematical properties of these novel topological indices was investigated. It was found that a lower and upper bounds for the simple connected graphs. It can be interesting to find the exact value of the $e v$-degree and $v e$-degree Zagreb indices of some graph operations such as; direct, Cartesian, corona, tensor, hierarchical and generalized hierarchical product of graphs for further studies. It can also be interesting to investigate the relations between the $e v$-degree and $v e$-degree Zagreb indices and the other well-known topological indices.

\section{References}

[1] M. Kuanar, S. K. Kuanar, B. K. Mishra, I. Gutman, Indian Journal of Chemistry-Section A 38A, 525 (1999).

[2] M. Randić, New Journal of Chemistry 20, 1001 (1996).

[3] M. Randić, M. Pompe, SAR and QSAR in Environmental Research 10, 451 (1999).

[4] M. H. Sunilkumar, Applied Mathematics and Nonlinear Sciences 1,345 (2016).

[5] M. Chellali, T. W. Haynes, S. T. Hedetniemi, T. M. Lewis, Discrete Mathematics 340, 31 (2017).

[6] H. Wiener, J. Am. Chem. Soc. 69, 17 (1947).

[7] R. Liu, X. Du, H. Jia, Bull. Aust. Math. Soc. 94, 362 (2016).

[8] H. Mujahed, B. Nagy, Acta Crystallogr. Sect. A 72, 243 (2016).

[9] M. Knor, R. Škrekovski, A. Tepeh, Discrete Appl. Math. 211, 121 (2016).

[10] I. Gutman, N. Trinajstić, Chemical Physics Letters 17, 535 (1972).

[11] B. Horoldagva, K. Das, T. Selenge, Discrete Appl. Math. 215, 146 (2016).

[12] A. Ali, Z. Raza, A. Bhatti, Kuwait J. Sci. 43, 48 (2016).

[13] S. Ediz, Mathematiche 71, 135 (2016).

[14] M. Randić, Journal of the American Chemical Society 97, 6609 (1975).

[15] R. K. Kincaid, S. J. Kunkler, M. D. Lamar, D. J. Phillips, Networks 67, 338 (2016).

[16] A. Banerjee, R. Mehatari, Linear Algebra Appl. 505, 85 (2016).

[17] R. Gu, F. Huang, X. Li, Trans. Comb. 5, 1 (2016).

[18] B. Furtula, I. Gutman, J Math. Chem. 53, 1184 (2015).

[19] W. Gao, M. K. Siddiqui, M. Imran, M. K. Jamil, M. R. Farahani, Saudi Pharmaceutical Journal 24, 258 (2016).

[20] W. Gao, M. R. Farahani, L. Shi, Acta Medica Mediterranea, 32: 579 (2016). 